\title{
HABLA COMO HOMBRE: EL RUIDO EN LAS CRÓNICAS DE PEDRO LEMEBEL*
}

\author{
Héctor Andrés Rojas** \\ Universidad de Chile-Conicyt
}

\section{RESUMEN}

El presente artículo realiza una revisión de los principales mecanismos utilizados por Pedro Lemebel en sus primeros libros de crónicas, para visibilizar una identidad marginal y subversiva, que disputa la apropiación del imaginario nacional en la literatura chilena. El estudio establece mecanismos recurrentes con los que el cronista logra plasmar un sentido político a su escritura para visibilizar una historia nacional que ha sido invisibilizada por el discurso oficial.

Palabras Clave: Lemebel, crónica, masculinidad, visibilización, ruido.

SPEAK LIKE A MAN: THE NOISE IN

THE CHRONICLES OF PEDRO LEMEBEL

\section{Abstract}

This paper makes a review of the main mechanisms used by Pedro Lemebel in his first books of chronicles, to make visible a marginal and subversive identity that is contesting the ownership of the national imagination in Chilean literature. The study establishes recurring mechanisms by which the chronicler shows a political sense to his writing to make visible a national history that has been made invisible by the official discourse.

Keywords: Lemebel, chronicle, masculinity, visibility, noise. 


\section{UNA ESCRITURA RUIDOSA}

Es indudable que la escritura de Pedro Lemebel es una de las más significativas y reconocidas de la literatura chilena actual. Ha sido leído, trabajado y estudiado enormemente. Las razones para volver a la obra de Lemebel y releerla, entonces, responden a una carencia en el estudio de su lengua, una lengua ruidosa y móvil que, por una parte, es el centro de su escritura, y que, por otra, ha sido ignorada en cuanto a su potencialidad política que permitiría abrir una nueva línea de análisis. Decimos que se ubica en un espacio que no ha debido compartir porque la literatura de Lemebel se enmarca en la "demostración" (como efecto escritural que trabajaremos) de una sociedad que está siendo apropiada o reapropiada por sujetos que comienzan a sentir como suyos espacios que antes les eran negados; una o unas identidades que habían sido silenciadas, habladas, y ensombrecidas, son recogidas por Pedro Lemebel haciéndose cargo de una discusión social y política a través de una respuesta lingüística y discursiva. Ello servirá de medio y de estrategia discursiva para que construya un sujeto único que es él mismo, un sujeto que posterga la representatividad colectiva con tal de ponerse en el centro de la escritura. Instalamos a partir de esta diferenciación la noción de lengua maquillada (de lo marginal que realza todos sus rasgos de subalternidad para generar un sujeto marginalizado representante de este borde social que derivará más tarde en un sujeto único, consecuencia última de este maquillaje). El sujeto único es distinto de lo representado con el maquillaje de lo marginal y su diferencia representa la marca ruidosa de la escritura de Lemebel.

Llevaremos a cabo un estudio literario que toma herramientas de la lexicografía para describir y explicar los neologismos presentes en las crónicas que analizaremos. A partir de esto podremos observar los usos lingüísticos de Lemebel en sus crónicas con fines estilíticos y políticos. Intentaremos explicar cómo, desde los procedimientos lingüísticos de creación léxica, vinculados en un contexto sintáctico y social, el discurso va situando lugares específicos y estratégicos de crítica literaria, política y social.

La forma novedosa de hacer discurso en Lemebel a través de la lengua no es un retrato de la manera en que la lengua conecta al individuo con su entorno, es más, lo que hace es crear un artificio, el del ruido. Es el proyecto escritural que se declara en el «Manifiesto (hablo por mi diferencia)», uno de los textos más conocidos y citados de Loco afán. Crónicas de sidario (1997). Hablar por la diferencia

* La primera versión de este artículo fue la tesis La escritura ruidosa: Estudio lexicográfico sobre la visibilización en la lengua de Pedro Lemebel para optar al grado de licenciado en Lengua y Literatura de la Universidad Alberto Hurtado, en Santiago de Chile, en el año 2007. Agradezco las revisiones y sugerencias de los profesores Abelardo San Martín e Ignacio Álvarez durante ese proceso. Todos los cambios posteriores que puedan haber alterado ese documento inicial son de mi entera responsabiliad.

** E-mail: hector.rojas1985@gmail.com. 
es, en términos lingüísticos, comprender las restricciones culturales del uso de la lengua, considerando, como dice Halliday, que «una lengua consiste en parte en aprender a librarla de las restricciones del entorno inmediato» (43). Hablar por la diferencia es comprender esas restricciones dadas por los prestigios lingüísticos, valoración de algunos usos por sobre otros, vestirse de la lengua no prestigiada y alzar desde esa posición una batalla de resignificación.

La individualidad de la figura de Lemebel cifra constantemente la narración -en apariencia consignadora o anecdótica- para instalarla en un centro reflexivo y crítico a partir de la incorporación de formas de habla y creación de léxico; de este modo, el texto logra significar en cuanto a escritura complementando lo enunciado, es decir, se trata de un discurso que se va reforzando a través de estrategias léxicas y sintácticas. Para esto, la noción de escritura que empleamos tiene que ver con la descrita por Roland Barthes en El grado cero de la escritura: «El lenguaje nunca es inocente: las palabras tienen una memoria segunda que se prolonga misteriosamente en medio de las significaciones nuevas. La escritura es precisamente ese compromiso entre una libertad y un recuerdo, es esa libertad recordante que solo es libertad en el gesto de la elección, no solo ya en su duración» (24).

Será por lo tanto, como lo representado, una respuesta lingüística a la marginación de espacios que ya no solo serán físicos, sino también culturales, porque habrá una lengua de poder que no reconoce ciertas formas de representación y se niega a la movilidad escritural, aspecto tan propio de la escritura de Lemebel como desarrollaremos más adelante. En otras palabras, a partir del reconocimiento de una tradición lingüística, esta escritura quiere distanciarse de la práctica social silenciadora, que ha impedido como forma de cultura que un sujeto subalterno tenga voz.

Se suele referir al trabajo de Gayatri Ch. Spivak por la pregunta "ipuede hablar el sujeto subalterno?» (SPIVAK 175), que termina concluyendo en una negativa, porque el único atisbo de voz del sujeto subalterno -en el texto una mujeratenta contra el mismo sujeto; representado por el suicidio de Bhuneswari, que se quita la vida mientras está menstruando para desprenderse del ritual que la mantenía sujeta a una tradición que la callaba (SPIVAK 227). Podemos reconocer que este único gesto en que el sujeto subalterno cobra voz termina con el sujeto mismo, lo que es una contradicción porque es necesario el sujeto para que exista el discurso. La pregunta, por tanto, sigue instalada: ¿puede hablar el sujeto subalterno? Por cierto, el sujeto que instalará Lemebel será un sujeto existente y hablante, que será capaz de construir un discurso sin abandonar la subalternidad, lo que veremos en el desarrollo de este trabajo.

A partir de esta premisa, que el sujeto subalterno no puede hablar, buscamos instalar la escritura de Lemebel como un impulso que logra erigirse en una escritura para invertir la invisibilización. Lo llamamos de esta forma y no solo decimos visibilización porque, además de mostrar una identidad, la expresión da cuenta de un proceso previo que la invisibilizó. Esto se llevará a cabo a partir del uso de disfemismos y el rescate de voces reprimidas, con lo que se podrá exhibir un sujeto que a través de la lengua cobra real importancia y es suficientemente visible. Sujeto portador de una lengua imposible de desoír (Olea 12), que provoca en las miradas de los otros la fuerza centrípeta que mencionamos antes, sujeto que se configura como 
un flâneur invertido, sujeto que tendrá a su alrededor lo que Karina Wigozki llama mirada moralizante y mirada represora, un ojo vigilante y penitencial (13).

\section{EL ESTUDIO LINGÜÍSTICO COMO HERRAMIENTA POLITIZADA}

La escritura de Lemebel logra combinar una serie de intenciones literarias y sociales en su escritura; es decir, hay una forma especial y llamativa de enunciación que nos interesa estudiar para, a través de ella, entender la escritura como una forma incisiva de discurso. Lo más llamativo es que la solución a esta intención escritural no se responde simplemente desde la temática, sino que es combinada con la forma de construir su discurso. Es esta la razón por la que nos aproximamos desde la lingüística a este sujeto-discursivizado que es la figura autoficcional de Pedro Lemebel. Como hemos podido investigar en los estudios críticos sobre la obra de Lemebel, normalmente solo se llega a bordear tópicos lingüísticos sin entrar completamente en ellos.

En la literatura chilena en general solo tenemos como antecedente los Estudios mistralianos de Rodolfo Oroz. En este estudio Oroz señala que el análisis detallado de los aspectos morfológicos y semánticos de su vocabulario "permitirán tal vez apreciar mejor algunas fuentes de su inspiración, conocer algo más de sus estados de alma o descubrir también ciertas inclinaciones más recónditas de nuestra poetisa» (45). En este estudio se intenta insistentemente relacionar el estudio lingüístico con la autora real, en el afán de dilucidar su estado anímico, espiritual y su contexto de escritura. Oroz niega una intención autorial a niveles que hoy resultan insólitos, como cuando explica los neologismos que advierte en su poesía por causas azarosas en vez de asumir un propósito escritural. Así lo vemos en el siguiente fragmento del texto, donde explica las posibles causas que la llevarían a utilizar este lenguaje derivado de otras formas no convencionales ni reconocidas:

En ciertos momentos, la fugacidad de su inspiración le exigía una expresión inmediata, pero la palabra precisa tal vez no acudía con la presteza necesaria, o sintiendo la carencia del vocablo apropiado o buscando la eufonía y un afecto especial, fue inducida a crear nuevas voces que dan a su lenguaje un matiz peculiar (Oroz 60).

Nos parece por lo tanto indispensable hacer una precisión en cuanto a la forma en que Oroz entiende el lenguaje, puesto que nuestras propias reflexiones no se adscribirán a la consideración del lenguaje como norma, según la cual los diccionarios actuarían como manuales de habla. Si pensamos la lengua como expresión y los diccionarios como registros de lengua, eliminaremos entonces las categorías de habla correcta o incorrecta, y las diferencias lingüísticas, en vez de referir al acierto

${ }_{1}$ Únicamente tenemos como referente el manuscrito inédito de Raquel Olea donde analiza la lengua ruidosa en Tengo miedo torero (2007). 
o al error, referirán a causas múltiples que pueden ser comprendidas, por ejemplo, por los estudios sociolingüísticos o psicolingüísticos, entre otros. Un antecedente de esta discusión la encontramos en el artículo de Ambrosio Rabanales «A propósito de la obra ¡Usted no lo diga! ¿Qué es hablar correctamente?», donde señala que la RAE es «sólo un registro objetivo de las estructuras de la misma, con una primordial finalidad informativa, y no prescriptiva» (228). En nuestro caso y para efectos de este análisis de la lengua de Lemebel, intentaremos precisar la innovación lingüística como herramienta discursiva politizada.

Para el análisis lingüístico consideraremos el estudio de Mervyn F. Lang, Formación de palabras en español, que hace una descripción detallada y ejemplificada de la formación de palabras en nuestra lengua. Además, consideraremos el trabajo de Abelardo San Martín, quien realiza un estudio de creación léxica en el registro festivo del diario La Cuarta, donde explica que la creación de palabras «está al servicio del afán expresivo del hablante... de la neología referencial, en que la creatividad léxica se orienta a satisfacer las necesidades designativas de las nuevas realidades» (213). En este estudio, el autor señala una serie de neologismos que exceden los márgenes de los registros de habla $(D R A E)$ y también la incorporación de americanismos y chilenismos. Nos parece necesario subrayarlo porque aquí se explicará una construcción discursiva que excede la necesidad de comunicarse, ampliando el abanico de posibilidades lingüísticas a estilos y formas intencionadas de construir discursos, en las que el lenguaje ya no es solo un medio, sino que también es capaz de significar por sí mismo.

Nuestro corpus está constituido por las crónicas de Lemebel. Son precisamente las crónicas el espacio en donde más se ha desarrollado el escritor; recordemos que estas primero fueron leídas o publicadas en diversos medios, como las revistas Página Abierta, El Canelo, Lamda News, los suplementos Alter-nación y La Gacela del diario La Nación; Radio Tierra y el periódico The Clinic, entre otros. Que sean estos medios y no otros sitúa a Lemebel en un lugar estratégico, tanto para él como escritor como para quienes deciden publicar sus textos. Su peregrinaje por los diferentes medios habla también del lugar en el que se fue instalando cada vez con más firmeza: desde el margen puro a un imaginario nacional aceptado, y luego a un innegable lugar en el mercado. Los primeros medios que dieron un lugar a Lemebel, como Página Abierta, son margen puro y recogen las crónicas publicadas entre 1991 y 1993, textos que darán forma a La esquina es mi corazón (1995), como se señala al final de este mismo libro. En la misma línea está el libro De perlas y Cicatrices, compuesto por crónicas radiales emitidas por primera vez en la Radio Tierra, también situada en el margen puro y relacionada, por tanto, con el proyecto discursivo que representa el autor. Pero nos encontramos con situaciones paradojales, como las publicaciones en La Nación: aquí el margen se instala como un paisaje necesario para la visión panorámica de país que quiere construir este medio representante de un proyecto editorial marcado por la apertura. Luego tenemos el caso del periódico The Clinic, que aparentemente es la instalación en el margen del poder; este medio, sin embargo, tiene la particularidad de ser una forma de convertir el margen en mercancía. No es casual que precisamente de allí salga la selección de crónicas que conforman Adiós Mariquita Linda (2004). Para J. Agustín Pastén este libro 
sería la forma en que una identidad supuestamente minoritaria se vende, «de ahí que el radio de acción se extienda y que se haga necesario un "glosario del autor"» (138).

Sería un hito en la transformación de Pedro Lemebel como sujeto confrontacional a sujeto comercial, y por lo mismo analizaremos solo las dos primeras selecciones de crónicas, donde se genera la relación de un sujeto escritor y un sujeto político, porque es en este cruce de doble interés autorial en el cual se produce una respuesta lingüística significativa, pues en la medida en que el escritor se relaciona con el mercado irá transformándose, más que en estrategia discursiva, en una necesidad de marcar autoría.

Nuestro estudio hará referencia en general a la obra literaria de Lemebel, aunque el análisis lingüístico y textual se centrará en sus dos primeros libros de crónicas: La Esquina es mi Corazón (1997) y Loco Afán: Crónicas de sidario (2004). Estas crónicas, al haber sido publicadas previamente en otros medios, poseen una relación más cercana con los lectores que la literatura producida solamente en editoriales, tal como señala Mateo del Pino: "Se produce una suerte de "panfleteo" en el que los textos se dispersan, transitan de un medio a otro, para luego ser recogidos, juntados, e ingresados "a la academia librera"» (citado en PAstén 20).

Por otro lado, el género crónica posee sus particularidades. En líneas generales, las crónicas "históricamente, [...] aparecen en períodos de cambio, cuando se acometen empresas o surgen transformaciones que es necesario consignar» (DE LOS Ríos 128). La autora señala que un cronista contribuye con su escritura a la creación de imágenes que construyen una suerte de memoria colectiva (128); así, la experiencia particular del cronista, al estar escrita, se fija en el tiempo y, al ser leída con posterioridad, instala esta memoria que se escapa a los límites del escritor.

La escritura ruidosa de Lemebel desequilibra la ciudad acostumbrada a invisibilizar a los sujetos, y de este modo Lemebel se instala como un flâneur invertido, porque este sujeto que se paseaba por las calles de París mirando a los demás como un detective (BENJAMIN 55), ejerciendo una fuerza centrífuga a partir de sí mismo, aquí generará una fuerza centrípeta atrayendo las miradas y por lo tanto apareciendo y dándose existencia como parte de esta ciudad: el sujeto se apropia de la ciudad. París modernizada y el Santiago de Lemebel son ciudades temporalmente distanciadas, pero que cumplen con las características físicas para permitir el callejeo y con eso la existencia del flâneur (BENJAMIN 51). Esto, visto desde el lenguaje, se manifiesta en la presencia de un léxico creativo que resulta ruidoso y atrayente. Entender la crónica como una forma de construir memoria colectiva, por supuesto es una definición limitada y limitante, porque la crónica muestra una serie de matices según su utilización, lo que advierte Pastén: «En el transcurso de su "cronicar", Lemebel no se cansa de denunciar la explotación y la opresión que sufren éstos [sujetos subalternos, particularmente las locas], tampoco de mostrar la otra cara de la historia oficial» (126), por lo que cronicar desde este punto de vista sería equivalente tanto a construir memoria como a deconstruirla para reconstruir sobre sus restos una nueva historia que pretende desmentir a la anterior. Aun así, crónica en términos generales será esta gran radiografía de una sociedad o, más bien, considerando que la crónica históricamente es entendida como dicha radiografía, Lemebel construye un texto ficcional (tenga o no asidero en la realidad), y lo presenta como si fuera una crónica. 
En nuestro análisis, Lemebel construye previamente este retrato de la sociedad, en el cual la característica de previo permite la incorporación de la intencionalidad, de lo que se quiere mostrar profundamente estilizado.

La importancia otorgada al lenguaje no es casual, tanto como medio de representación como en cuanto forma de segregación. El acceso a este elemento, su utilización y su recepción, ha determinado históricamente la marginación social, y además ha impedido que algunos sujetos figuren en la historia y permitido que otros logren posicionarse -como si-fueran los únicos o los neutrales.

Otro lenguaje permite señalar otras realidades, porque la lengua común vista como lengua ideal, además de ser siempre limitada, está marcada por la utilización que se ha hecho de ella; esa lengua manchada de ideologías no sirve para nombrarlo ni describirlo todo, porque es una lengua elitizada, masculinizada. Elaine Showalter señala que

los grupos dominantes controlan las formas o estructuras en que la conciencia puede articularse. Por ende, los grupos silenciados deben instrumentar sus creencias a través de las formas permitidas por las estructuras dominantes [...] todo lenguaje es el lenguaje del orden dominante (103).

Por lo mismo, la escritura de Lemebel, en cuanto escritura que genera un lenguaje nuevo, es capaz de alumbrar el espacio de oscuridad que no considera el orden patriarcal, pudiéndose leer a dos voces como sucede con el discurso femenino que "encierra una historia "dominante" y una "silenciada" (SHOwalter 109), porque el lugar del dominado le otorga una vista panorámica del proceso de dominación del que es parte.

El sujeto que produce un discurso tendrá múltiples conexiones, tanto con los aparatos de poder como con las víctimas de esta dominación, y también se conectará con los imaginarios y el deseo. Néstor Perlonguer recoge esta misma idea en el concepto de neobarroso y explica que "su juego actual parece dirigido a montar la parodia, la carnavalización, la derrisión, en un campo abierto de constelaciones, sobre (o a partir de) cualquier estilo» (115), instalando un lenguaje complejo y repleto de sentidos hasta el absurdo. Estos elementos que nunca dejan de significar desembocan en una movilidad infinita, producto de los múltiples elementos dispuestos para la significación que son imposibles de estabilizar.

El lenguaje movedizo de Lemebel ya fue planteado por Raquel Olea como un rasgo importante de su escritura:

Lemebel recurre a la imagen del revoloteo para señalarla [la escritura] ruidosa y situada aún en la superficie del lenguaje. 'cual abejorro zumbón, iba y venía por la casa', para simbolizar en ese ruido (in)significante pero imposible de desatender la representación de lenguaje-ruido, de un habla reciente, profusa en su emergencia, imposible de desoír (212).

De esa manera instala una vez más el lenguaje como la forma de atraer las miradas, esta vez de los lectores que no pueden no atender a las construcciones enrarecidas que están ocurriendo en el texto. 
El lenguaje también sirve para nombrar lo que no ha sido nombrado, como señalamos refiriéndonos a la paradoja de la marginalidad en el texto de Showalter. Es así como en «las crónicas de Loco Afán transparentan la necesidad de nombrar -nombrar víctimas, nombrar muertos y así enfrentarse con historias que dan a la homosexualidad un lugar en la política» (Franco 17). Todos estos nombres que aparecen han sido oscurecidos por el discurso oficial. Nombrarlos es instalar en la discusión a personas que para el gran discurso no existen. Ahora bien, el sida, la muerte, el homosexual sidoso son parte del discurso oficial, son tópicos reconocibles, a los que se les quita importancia; es deber del sujeto político, entonces, invertir esta invisibilización a través de la escritura. Si lo consideramos como forma de arte podemos relacionarlo con la teoría de la literatura de los formalistas rusos, donde se especifica que

el carácter estético se revela siempre por los mismos signos. Está creado conscientemente para liberar la percepción, del automatismo. Su visión representa la finalidad del creador y está construida de manera artificial para que la percepción se detenga en ella y llegue al máximo de su fuerza y duración (SHKLovski 68-69).

Las crónicas de Lemebel, recordando la forma barroca de construcción discursiva, funcionan superponiendo imágenes una junto a la otra, de modo de hacer compuestos de significado que obligan a ver nuevamente el texto, tal como ocurre en el artificio que busca la percepción. Un buen ejemplo de esto es cuando Loba Lamar está muriendo a causa del sida y su muerte comienza a asemejarse cada vez más a la maternidad:

El SIDA para la Loba trastornada, se había transformado en promesa de vida, imaginándose portadora de un bebé incubado en su ano por el semen fatal de ese amor perdido [...] noche tras noche la oíamos llamarlo, y tratábamos de complacerla en sus antojos de Lola parturienta [...]. Nos puso a todas a tejer chales y gorritos y chalequitos y botines para su nene (Loco Afán 44).

La superposición de dos imágenes que se contraponen, como ocurrió en el ejemplo anterior, termina generando nuevos niveles de significado cada vez más complejos, como ocurrirá también en los modos de formación de palabras que veremos más adelante.

Leonidas Morales dice que el narrador puede instalar en el texto un testigo, y que lo particular es que este testigo es también parte de la acción (59). Por su parte, Fernando Blanco ha dicho sobre Lemebel que "formas discursivas como la revelación del secreto, el rumor, la negación civil al olvido constituyen la narrativa principal del rompimiento del pacto de silencio de la que Lemebel es la voz principal» (29). Referimos a esto precisamente por la cantidad de roles que ocupa el testigo a través de las crónicas, la cantidad de roles también que ocupa el mismo Lemebel dentro de los textos. Por ejemplo, Pastén señala a propósito de Adiós mariquita linda que «el simple voyeur se transforma en lo que podríamos llamar autor-narrador-protagonista» (134). Evolutivamente, para este crítico, Lemebel se va transformando en el protagonista, poniéndose por completo sobre y dentro del texto. Pero 
no es solo eso: Lemebel no solo se transforma en este autor-narrador-protagonista, porque si así fuera nos bastaría con decir que los textos de Lemebel tienden a tener un narrador autodiegético (GenetTe 300); consideramos que el ejercicio operante en las crónicas de Lemebel tiene que ver con un flâneur invertido, que no solo se pone en el centro de la escritura, sino que atrae inevitablemente las miradas, a diferencia del flâneur parisino que se perdía en la multitud.

Pertenecer al grupo desplazado permite escribir acerca de lo otro con propiedad y base empírica. A momentos esta contracultura puede funcionar denunciando la violación de la que ha sido víctima, ya no lingüística ni culturalmente, sino física y ciudadanamente en la actuación real y callada escrituralmente. Por ejemplo, en la crónica «La música y las luces nunca se apagaron» (La Esquina 119), que relata el incendio en la discoteque Divine de Valparaíso, el 4 de septiembre de 1993, se desmiente escrituralmente lo que se mencionó temáticamente como causa del incendio: una falla eléctrica. El autor afirma, al final de la crónica y en el título, que la música $y$ las luces nunca se apagaron, una expresión que puede ser metafórica pero que leída literalmente vuelve ilógico el informe policial y acusa una violación a los derechos humanos y a la integridad física de quienes estaban en ese lugar.

De este modo se desintegra la idea de lo oficial como consecuencia natural. Los textos de Lemebel buscan generar nuevos instrumentos de análisis, como los que Jean Franco menciona que son generados por la teoría feminista, al buscar generar un cambio en el estudio de la literatura de modo sustancial (32). Lograr que los informes oficiales ya no sean oficiales realmente, provocar en el lector una desconfianza hacia lo que se le presenta para que pueda cuestionar por sí mismo lo que le parece deseable y creíble; ampliar el universo de posibilidades, ampliar la competencia literaria y cultural de los receptores de esta literatura, esos son algunos de los efectos de la escritura ruidosa de Lemebel. Por lo tanto, esta identidad previamente ultrajada se volverá un sistema ultrajador hacia el discurso oficial, cifrándolo, haciéndolo inestable e incompleto.

\section{LA INAGOTABLE IDENTIDAD DE LA LOCA}

El homosexual es el sujeto problemático que se desplaza silenciosamente entre distintos deseos e identidades, el sujeto difícil de clasificar. Por eso es más amigable la figura de "la loca», como lo denomina Lemebel, este homosexual sin doble vida, que abiertamente es un sujeto marginal pero no ambiguo, un sujeto que no trasgrede los géneros ni las sexualidades de los otros. Este sujeto se clasifica y, al estar clasificado como un otro, por más diferente o indeseable que se le considere, ya no es problemático, a diferencia de lo que ocurre con la Manuela de El Lugar sin Límites de José Donoso, que es un personaje a veces hombre y a veces mujer, un personaje que critica los discursos sexuales conservadores porque su ambigüedad termina reflejando la ambigüedad de todos los otros personajes. Entonces, si consideramos que este sujeto loca no es problemático desde la clasificación de la identidades, debemos entender cómo opera para efectuar la desestabilización que antes mencionábamos, de qué manera logra ser problemático, lo que tendrá que ver estrechamente con los 
espacios y la reocupación de estos, ya que estos han sido nombrados como propios exclusivamente por el sujeto presentado como único, quien con el solo gesto de la existencia de un sujeto loca se siente invadido. Identitariamente, por tanto, la loca no es problemática en cuanto loca, se vuelve problemática en la medida en que se polariza hombre o se polariza mujer, como sucedía con la Manuela.

Si lo llevamos al espacio social, vemos cómo la loca es el personaje que delata el error, la falla. La loca es el personaje que advierte que el orden no funciona ni es capaz de clasificar a todos, la loca por tanto es la fisura que se oculta. Por eso en la literatura de Lemebel la loca es el personaje central, es la loca quien realiza la reocupación de los espacios que habían sido designados por el aparato de poder. La loca inevitablemente deambula, porque en la ciudad organizada no hay un espacio para ella -antes era el burdel-, por eso se pasea por todas partes errando, culebreando, zigzagueando como el flâneur invertido, que, a la vez que mira, pasea por la ciudad atrayendo las miradas.

\section{ANÁLISIS DE LA LENGUA RUIDOSA}

Al analizar la escritura de Lemebel desde una perspectiva lingüística encontramos dos líneas de análisis importantes. La primera tiene que ver con la inclusión de las voces de los otros no prestigiados y no dominantes, lo que se advierte en el uso de chilenismos y voces reprimidas; la segunda tiene que ver con la creación léxica y sus diferentes recursos de formación, los que llamaremos «lemebelismos». Estos últimos a menudo no son creaciones nuevas por completo, sino que son derivados o términos con alteraciones en su significado. Para hablar de chilenismos consideraremos el registro del Diccionario de la Real Academia Española (DRAE) y el Diccionario ejemplificado de chilenismos $(D E C H)$.

A continuación, presentamos un análisis seleccionado de los términos más significativos para ejemplificar los procedimientos de creación léxica presentes en las crónicas de Lemebel².

\subsection{Cambio semántico}

El cambio semántico implica un desplazamiento de la relación entre significante, significado y referente (SAN MarTín 224). En la poética de Lemebel este resultó ser un recurso muy productivo, y principalmente se da porque palabras ya existentes o que derivan de otras cambian su significado a través de una metáfora.

2 Se excluyen de este artículo otros procedimientos de creación léxica que fueron descritos durante la investigación, pero que no resultaron tan distintivos de la escritura de Pedro Lemebel, como verbalización, metonimia, calco, nominalizaciones, adjetivación y variación sustantivo-adjetivo. 
La utilización del lenguaje va matizando y enriqueciendo su descripción de los sujetos retratados y, por supuesto, de sí mismo. El desplazamiento es un elemento fundamental, hablamos de una utilización que es condescendiente con la figura movediza de la loca dentro de la ciudad, y así también de la lengua.

Tomemos como ejemplo dos verbos:

Serpentear: verbo. Manera que tiene la loca de desplazarse por la ciudad («cada noche cruza el enramaje de sus plumas y no le importa coagularse con otros hombres, que serpentean los senderos como anacondas perdidas" [La Esquina 25]). Culebrear": verbo. Manera que tiene la loca para desplazarse por la ciudad ("la Regine, cuando bolsa en mano culebrea entre los puestos de la Vega Central» [Loco Afán 26]).

Ambos son verbos que designan acciones a realizar, un desplazamiento; pero no es casual que refieran a acciones descritas por estos animales en particular. A través de la caracterización de la acción se define indirectamente al sujeto, ya que quien serpentea o culebrea está teniendo un comportamiento no humano. Esto respondería a una construcción metafórica del tipo ontológica según la clasificación realizada por Lakoff y Johnson (63).

Por tanto, en el lenguaje de Lemebel se conecta la movilidad con la figura del flâneur invertido, debido a que, al decir serpentear o culebrear para describir el movimiento del homosexual a lo largo de las historias, se instala también la imagen de la loca paseándose por la ciudad.

La loca que se pasea por la ciudad no camina sino que culebrea o serpentea, porque es la forma en que se instalan las inestabilidades, porque este movimiento es difícil de percibir, difícil, por tanto, de clasificar y de controlar. Podríamos hablar de un sujeto que se escurre por la ciudad, que se filtra por los lugares que se han designado para determinados sujetos y negados para otros desde su ordenamiento; es gracias a este desplazamiento que logran incorporarse. Se vuelve un sujeto con un desplazamiento no acusable, pero siempre sumamente visible.

Consideremos la siguiente palabra:

Tarántula: sust. Sinónimo de mano. Refiere a la mano que se desplaza como si fuera una tarántula («la loca suelta la tarántula por la mezclilla erecta del marrueco» [La Esquina 163]).

Aquí hay un cambio semántico que se concreta a través del acercamiento metafórico entre mano y tarántula. Esta palabra es un concepto clave en la crónica «Tarántulas en el pelo» de La esquina es mi corazón, donde la loca peluquera con sus manos/tarántulas desplaza el contacto cautelosamente sin ser advertido por los otros: con el gesto de amasar a quien le está cortando el pelo o peinando, lo confi-

${ }^{3}$ DRAE culebrear: De culebra. 1. intr. Andar formando eses y pasándose de un lado a otro. 
gura como un sujeto que se proyecta en la cabeza de su clienta; las manos/tarántulas en ese caso son manos hacedoras que fabrican sujetos, manos que pueden desplazarse silenciosamente -como las tarántulas- $\mathrm{y}$, de ese modo, evitar la resistencia del sujeto que será amasado. Es la loca la que se construye a través de una proyección en la cabeza ajena. De esta manera el cambio semántico lograría formar figuras equivalentes, porque al utilizar «tarántulas» por "mano» el significado se enriquece con la carga semántica de las dos palabras que convergen en ella: mano y tarántula.

\subsection{COMPOSICIÓN ORTOGRÁFICA}

Este lenguaje movedizo en Lemebel pone en escena su dualidad como inestable, incluso como interpretable. Del mismo modo podemos ver esta característica en el antiguo carnaval medieval: «Esta visión, opuesta a todo lo previsto y perfecto, a toda pretensión de inmutabilidad y eternidad, necesitaba manifestarse con unas formas de expresión dinámicas y cambiantes (proteicas) fluctuantes y activas» (Bajtín 16). Podemos verlo en el uso, muy productivo, del recurso llamado composición ortográfica, que implica un estadio intermedio entre la palabra y la frase (LANG 91). Este recurso es sumamente infrecuente en el español. Abelardo San Martín confirma esta tendencia en su estudio de creación de léxico en La Cuarta, donde señala que «este recurso resultó improductivo en comparación con la notable proliferación de lexías originadas por derivación, especialmente mediante sufijación apreciativa» (228).

Al hablar de los tipos de compuestos, San Martín señala que la tendencia actual es obviar la restricción ortográfica y considerar como compuestos aquellos sintagmas cuyos constituyentes, aunque no estén gráficamente unidos, conforman una unidad de sentido (228). Este será un recurso sumamente frecuente en Lemebel, por lo que nos haremos cargo de sus variantes.

Maricócodrilo: sust. Composición de los lexemas maricón y cocodrilo, por el dicho «lágrimas de cocodrilo» y la característica de llorar sin tristeza («No quiero presionarte con lágrimas de maricócodrilo moribundo» [Loco Afán 55]).

En este ejemplo es claro el valor literario por sobre la función comunicativa. «Maricócodrilo» dialoga con un imaginario anterior, por eso es imposible de ignorar. Esta palabra aparece en la "Carta a Liz Taylor» (Loco Afán 55), quien, cuenta el emisor de la carta, debe ser uno más de los sidosos que le escriben para conseguir algo que puedan transar por dinero para comprar AZT, que es el primer medicamento utilizado para tratar el sida. Al mencionar en la carta que no desea presionarla con lágrimas de maricócodrilo, anuncia que su argumento no será la lástima sino un ejercicio retórico, de modo que se sitúa a Liz Taylor en un lugar de conveniencia en caso de ayudarlo; es definitivamente un elemento central en el ejercicio argumentativo de dicha carta.

Ahora bien, la poética de Lemebel es muy rica en su lenguaje y debido a esta forma en que construye significados y significantes, nos vemos en la necesidad 
de plantear nuevas categorías lingüísticas de creación léxica, como en los siguientes tipos de composición ortográfica:

\subsection{COMPOSICIÓN YUXTAPUESTA CON GUION}

Esta forma de composición ortográfica funciona sin síntesis ortográfica completa pero manteniendo dos lexemas unidos por un guion, y es de uso muy frecuente en Lemebel. Son estas precisamente las construcciones que producen una mayor dualidad semántica, al funcionar como ideas individuales pero a la vez generar un sentido nuevo.

Ano-arco: sust. Arco de fútbol, mencionado desde la relación metafórica de que hacer un gol equivale al acto de penetrar un cuerpo («los chicos se abrazan y estrujan estremecidos por el bombazo de un delantero que mete la pelota rajando el himen del ano-arco» [La Esquina 53]).

En este caso, la acción está situada en el estadio, lugar por tradición de la masculinidad, porque el fútbol se ha definido culturalmente como un deporte heterosexual. En este lugar profundamente valorizado aparece la ambigüedad de los sujetos que en la acción de meter un gol terminan penetrando este ano-arco de otro hombre que es el portero; un coito simbólico en la cancha para reflejar el deseo de los hombres bañados en sudor que se describen en las galerías donde se ha colado la loca. Este personaje está, por tanto, realizando un ejercicio de construcción de pares analógicos para categorizar algunas costumbres de esta sociedad, como la de encubrir un deseo homosexual legítimo. Ano-arco sugiere un comportamiento represor del instinto, un instinto que se disfraza (de fútbol, por ejemplo), pero finalmente un instinto compartido por todos.

Este tipo de compuesto utilizado por Lemebel es una forma sofisticada de construir nuevo léxico, porque al mismo tiempo que es una composición ortográfica, puede operar como homonimia o como paronomasia.

\subsection{COMPOSICIÓN YUXTAPUESTA CON GUION QUE FUNCIONA COMO HOMONIMIA}

Este tipo de composición ortográfica consiste en la combinación de dos o más lexemas que forman una unidad abierta, tal como vimos en la categoría anterior. La particularidad en este caso es que, al funcionar como homonimia, el compuesto se pronuncia como una palabra ya existente. El nuevo lexema resultante, aun cuando sea portador de más de un significado, no puede desconocer su significado en el sintagma.

Agrade-sida: adj. Forma estilística de «agradecida» que recuerda un hablante que se reconoce con voz femenina y que insiste en su estado de contagio («Te estaré eternamente agrade-sida» [Loco Afán 56]). 
Aquí vemos cómo esta composición ortográfica abierta, junto con completar el significado de la oración, otorga un segundo significado sobre el tema del sida y la petición de una joya a Liz Taylor para el tratamiento de la enfermedad (Loco Afán 55).

Lo que se hace en esta composición ortográfica, primeramente, es descomponer la palabra agradecida para reconstruirla con un significado enriquecido, por eso estas construcciones se presentan solo en determinadas crónicas, porque para elaborar este juego de significado es necesario utilizar el contexto en el que se encuentra la palabra que previamente es descompuesta. Es decir, agrade-sida solo podrá reemplazar a agradecida en circunstancias estrictas del contexto, porque lo que hay principalmente detrás de la escritura de Pedro Lemebel es una estrategia discursiva, por sobre un afán de crear un léxico nuevo.

Ciudad-anal (variación). Refiere a las prácticas ciudadanas, pero al estar separada con un guion posibilita un segundo discurso donde lo relativo a la ciudad es lo relativo también al ano («la selva rizada de una doncella por el túnel mojado de la pasión ciudad-anal» [La Esquina 161]).

El significado global sigue siendo referir a lo «ciudadanal» como característica propia de la ciudad, pero al plantearlo de este modo la ciudad también está siendo caracterizada, es una ciudad anal como carga peyorativa.

\subsection{COMPOSICIÓN YUXTAPUESTA CON GUION QUE FUNCIONA COMO PARONOMASIA}

Esta forma de creación léxica también puede ser vista como paronomasia, porque se verifica una transferencia del significado por la semejanza entre los significantes, característico de la conciencia escritural de Lemebel y de la dualidad de sentido que provoca. La diferencia con la homonimia es que en estos casos la representación fonética del compuesto resultante no será idéntica a una palabra ya existente, sino que solo será semejante.

Depre-sidas: adj. Forma estilística de «depresivas» («los escupos en el trago, los condones rotos, los exámenes AIDS falsificados de positivos, que llevaron al suicidio a varias depre-sidas» [Loco Afán 52]).

En este ejemplo, tal como ocurrió con agrade-sida, la composición ortográfica se basa en la similitud en la pronunciación. En ambos casos la construcción con motivo estilístico se compone en una de sus partes por la palabra sida, que es el tópico central de Loco Afán.

Si bien en el sintagma se inserta el compuesto utilizando estructuralmente el significado del lexema con el que se establece la homonimia o la paronomasia, esta forma de creación léxica incluirá un sentido adicional que se vuelve imposible de ignorar, que captura la atención del lector. Así, presentarlo de esta forma no solo tiene un sentido estilístico, sino que es capaz de cifrar la narración para connotar nuevos sentidos. 
En su estudio sobre los neologismos, Rodolfo Oroz se detiene en las formas de derivación no convencionales de Gabriela Mistral, ignorando que «es característico de la formación de palabras el hecho de que sus paradigmas son altamente irregulares e incompletos» (LANG 18). No queremos decir con esto que el estudio de Oroz sea innecesario, sino más bien conectar ese registro de neologismos con una característica propia de la lengua española. Es importante señalarlo, porque comparar a Lang con Oroz nos permite producir una línea evolutiva en el estudio de la lengua, que indica cómo se comprende el lenguaje en diferentes momentos de una disciplina, comenzando en una postura sumamente normativa hasta llegar al sistema interpretativo que tenemos hoy, en el cual lo que antes pudo ser llamado «error» es síntoma de algún proceso que está influyendo en los hablantes y por lo tanto en la lengua. Por eso nuestra investigación, como también los mismos textos analizados, dialogan con su entorno y su época. En otro momento histórico solo habríamos dicho que Lemebel fue un escritor altamente errático e inexacto en su escritura.

\subsection{UNIDADES FRASEOLÓGICAS}

Las unidades fraseológicas, al ser sintagmas, funcionan como una forma más compleja de denominar a los sujetos, pero pueden ser utilizadas como si no lo fueran, porque al construir estos sintagmas se logra a menudo fijarlos tal como son. Tienen además un tono festivo para referir a temáticas que, de no presentarse así, se mantendrían más distantes. En ese sentido operan describiendo un hacer más que un nombrar inmediatamente. Poseen una forma de frase, pero refieren a una descripción fija, asemejándose en ese sentido a los compuestos ortográficos:

Chupada de muela. Dicho de personas que impostan una postura engreída. Se relaciona con la acción de chuparse las muelas para estilizar el rostro ("habían llegado las regias, las famosas, las pitucas culturales, las chupás de muelas bajando del avión» [Loco Afán 13]).

En este caso, detrás de la descripción de la acción de chuparse las muelas se señala la actitud del sujeto que está siendo representado, pero la forma en que se lo expresa es mucho más rica lingüísticamente. También sucede con

Boca chupona. Boca de homosexual, a la que se le refiere disfemísticamente por haber practicado alguna vez sexo oral («Sólo un momento la homosexualidad lo tocó con la sed carmesí de su boca chupona» [Loco Afán 120]).

\subsection{LA FORMA NOVEDOSA DE HACER CREACIONES FESTIVAS}

Existen neologismos que, por sobre los criterios formales de creación léxica, responden a una intencionalidad meramente festiva. Por supuesto, el tono festivo no tiene por qué anular el funcionamiento de la palabra con su carga crítica o ideo- 
lógica. Veamos los siguientes ejemplos, que guardan relación con criterios de las voces al interior del texto.

Carroza: sust. Españolismo utilizado para denominar a los homosexuales mayores («En España, a los homosexuales mayores les dicen carrozas; así fueran arrugados carruajes, que sentados en la plaza de armas, esperan pacientes levantar algún cochero" [Loco Afán 111]).

Es evidente lo llamativa que resulta la forma antes citada, porque, al parecer, en nuestra comunidad de habla no existía previamente una palabra que definiera este concepto. Se recurre a esta expresión como un eufemismo que expresa cierta festividad o humorismo.

Otro ejemplo significativo es el que señalamos a continuación:

Sombra: sust. Sida, o el tenerlo ("Eso era en Talca... Se pegó la sombra dicen. Es bonito fijaté. Es como la sombra de los ojos. ¿Te fijas que los que tenemos SIDA, tenemos una mirada matadora?» [Loco Afán: 1997: 73]).

Lo que ocurre aquí es la utilización de un eufemismo que reemplaza a sida, eufemismo que además da cuenta de un proceso evolutivo que tiene relación con las fábulas de varias de las crónicas de Loco Afán. La aparición del sida opera como la nueva represión y estas sombras son los verdugos que persiguen a cada una de las protagonistas hasta su tumba. Ahora bien, la utilización de este eufemismo parece contradecir el criterio ruidoso que atraviesa la escritura de Lemebel, según el cual lo central es invertir esta invisibilidad a la que fueron sometidos los sujetos marginados, esta necesidad de no callar, de decirlo sin disfraces, cuya herramienta central sería el disfemismo, entendiéndolo como la forma de hablar de la forma más grotesca posible, a tal punto que sea imposible de ignorar. Entonces, ¿por qué se incluirían estos eufemismos, como sombra o el españolismo carroza, que es recogido en una crónica y que mencionamos antes? Lo que sucede es que Lemebel crea un sistema de voces diferenciadas y pone en el centro su propia voz, la que efectivamente será crítica y disfemística, y, por otro lado, estarán estas menciones, pero en la voz de otros.

Esta forma de transmitir las voces de las que no se quiere hacer cargo permite que, al terminar la lectura, se construya la imagen de Pedro Lemebel, el verdadero sujeto imposible de ignorar; un sujeto, por lo mismo con su propia voz.

Como hemos comprobado en el desarrollo del artículo, existen en Lemebel diferentes formas de creación léxica, y nos encontramos, por ejemplo, muchas formas de nombrar a la loca. La muestra más clara de esto está en la crónica «Los mil nombres de María Camaleón», donde el narrador señala:

La poética de sobrenombre gay generalmente excede la identificación, desfigura el nombre, desborda los rasgos anotados en el registro civil. No abarca una sola forma de ser, más bien simula un parecer que incluye momentáneamente a muchos, a cientos que pasan alguna vez por el mismo apodo (Loco Afán 58). 
Algunos ejemplos de estas denominaciones de la loca son descritas más adelante: la Desesperada, la Cuándo No, la María Silicona, la Maricombo, la Maripepa, la Loca de la Cartera, la Multiuso, la Pata Pelá, la Putifrunci, la Lola Puñales, la Si Me Llaman Voy, la Frun-Sida, la Bien Pagá, etc. (Loco Afán 60-61).

Los nombres de María Camaleón, que refieren a una persona o las muchas palabras para referir a encuentros íntimos o a sujetos homosexuales, nos hacen pensar en la sinonimia, porque habría un mismo referente, un mismo significado que cambiaría de significante. Sin embargo, esta sinonimia no es tal, porque si bien en líneas generales hay un mismo referente, cada vez que este sujeto es denominado se le van añadiendo características específicas, características no necesariamente estables. Así, al ir denominando una y otra vez, lo que se hace es un ejercicio de intensidad y especificidad de lo denominado. Si la sinonimia fuera perfecta sería absurdo que existieran sinónimos. Entendemos, por lo tanto, que hay un conocimiento acabado del lenguaje y de las posibilidades que este ofrece, de modo de ir generando con cada neologismo un nuevo nivel de intensidad y de especificidad en el texto que la fábula narrada no tendría por sí misma.

$\mathrm{Al}$ analizar minuciosamente el modo de formación de palabras presente en las crónicas de Lemebel nos encontramos con una elevada conciencia escritural de la posibilidad de combinar recursos, una especie de estructuralismo intencionado que conforma en sí mismo un discurso paralelo al discurso narrado. Así, ambos planos se van complementando.

Sobre los hallazgos lingüísticos encontrados, llama la atención que, si bien el español se caracteriza por utilizar mayormente sufijación apreciativa con «un extenso repertorio de sufijos denominados de manera diversa: apreciativos, afectivos o expresivos, que alteran semánticamente la base de un modo subjetivo emocional» (LANG 126), en Lemebel encontramos una tendencia clara a la composición ortográfica, sobre todo del tipo yuxtapuesto con guion del que no encontramos registro en un autor literario previo a este estudio. Este recurso sirve en las crónicas para crear discursos complejos con críticas cifradas, pero no se trata de un recurso frecuente en español, lo que hace aún más interesante analizar la escritura de Lemebel. «Borges habla de la "ineptitud para formar palabras compuestas" al comparar el español con el inglés y el alemán» (LANG 91). Este uso de nuevos recursos da cuenta de dos procesos. El primero se relaciona con el estudio de la lengua, y habla de la apertura a la nueva literatura chilena y latinoamericana, en la que podemos reconocer influencias de tendencias escriturales extranjeras; la influencia inglesa, por ejemplo, no se ve solo en la recepción de una lengua extraña como ocurría con dis-nai ("el coro de voces yanquis que prometen "dis-nai" o "esta noche"» [La Esquina 31]), sino que habría filtrado incluso la forma de escribir. Cabe resaltar que cuando hablamos de recepción de una lengua o de una cultura en Lemebel, siempre es la recepción de la capa desposeída e inculta, que representa la figura de la loca marginal. El segundo proceso se completa con la estrategia discursiva que hemos trabajado en esta investigación, donde los compuestos ortográficos, especialmente los que funcionan como homonimia y como paronomasia, otorgan al texto un nivel doble de sentido, que es lo que genera el ruido de esta lengua imposible de desoír. 
Este recurso, que se convirtió en el más productivo de nuestra investigación, fue ignorado en el estudio de Rodolfo Oroz sobre Gabriela Mistral. En dicho estudio se explica lo siguiente:

Haremos caso omiso de los sustantivos compuestos en que el segundo término actúa como una especie de epíteto del primero -fenómeno bastante común en la obra de Gabriela Mistral-. Y para mencionar sólo algunos, anotaremos aquí de Ternura: agua-rosa (p. 38); río-miel (p. 38), marnodriza (46).

Esta exclusión de los compuestos ortográficos en el estudio de la lengua de Mistral abre la posibilidad de una relectura desde la lingüística de sus textos, incluyendo estos elementos que fueron excluidos. Sin duda resultaría una investigación sumamente productiva y enriquecedora, pero excede ampliamente las fronteras de nuestra investigación. Aun así, nos parece importante advertirlo para futuros estudios sobre neologismos.

Con lo anteriormente señalado queda claro que la lengua de Lemebel es una lengua imposible de desoir como señalaba Raquel Olea, una lengua compleja que genera dualidades y que amplía el espacio del texto más allá de la narración, haciendo sumamente visible lo que antes debía disfrazarse.

Aunque como voz de lo marginado y como en toda literatura menor, hay una tendencia a lo colectivo, en las crónicas de Pedro Lemebel existe una instalación cada vez más fuerte de la figura de sí mismo, lo que genera una separación entre él y lo colectivo; es este flâneur invertido que mencionábamos antes el que atrae las miradas de los demás. Hay, por ejemplo, una separación entre lo que él menciona y lo que mencionan los otros, porque los otros tenderán siempre al eufemismo en los temas tabú, mientras que él preferirá siempre el disfemismo, expresión que se enfrenta a los discursos ya instalados y represores. Por eso señalábamos antes el caso de carroza o sombra, eufemismos que pone en la voz de los otros: los españoles y talquinos respectivamente. Pierre Bourdieu señala que «difícilmente podrían comprenderse las variaciones estilísticas si no es relacionándolas con las variaciones de la tensión del mercado» (53), ya que siempre estaríamos regulando nuestro discurso al contexto en el que es producido, es así como el autor afirma que "los discursos son siempre eufemismos inspirados en la preocupación por el "bien decir"”, por el "hablar como es debido" como si se tratara de fabricar productos de acuerdo con las exigencias de un determinado mercado" (Bourdieu 52). Lo que ocurre en el caso de Pedro Lemebel es que es capaz de comprender los parámetros de lo debido en el habla y decide desbordar estos límites, hacer ruido para visibilizar una voz que no es escuchada por el discurso oficial.

Lo antes señalado nos sirve para analizar lo que sucede con el glosario del autor en Adiós mariquita linda que, analizado desde el mercado -como lo hace Pastén- es innegablemente una estrategia de venta y de proyección editorial en el extranjero; sin embargo, al analizarlo desde la lingüística vemos que se trata de una vuelta a la forma de hacer discurso del autor. Lemebel define términos no estándares del español, como maricursi y mariloba, que serían un obstáculo para el mercado porque limita el público receptor. Este glosario, como nos señaló el 
autor, fue creado por petición de su editor. Lo interesante, sin embargo, es que el glosario no traduce, más bien vuelve a reforzar esta idea de flâneur invertido, funciona como un lugar para que Lemebel -supuesto representante de los marginados-se distancie de los otros, poniéndose frente a frente. Veamos el siguiente ejemplo: «Maraquear: putear, hacer la calle» (Adiós Mariquita 213). Su palabra - maraquear- es el disfemismo, y «hacer la calle» será el eufemismo comúnmente usado por quienes ejercen la prostitución. De esta forma se instala a sí mismo como centro de una escritura tan ruidosa que no se podrá ignorar. El glosario, pensado para traducir, termina revolcándose en su propio discurso, porque tanto el verbo maraquear como la unidad fraseológica hacer la calle son específicas y solo se diferencian en la forma disfemística de Lemebel, frente a la eufemística de los otros. Lo que sí podemos señalar, considerando las influencias del mercado, es que estas herramientas lingüísticas describen lo no dicho; al ir siendo estandarizadas pierden su efecto y se vuelven una especie de tic que efectivamente opera como marca de autor en términos comerciales. Además, debemos tener en cuenta que esta inclusión de un glosario no se repitió en los libros posteriores: Serenata cafiola (2008), Háblame de amores (2012), Poco hombre. Crónicas escogidas (2013), $\mathrm{ni}$ en su póstuma Mi amiga Gladys (2016).

Volviendo al tópico del maquillaje, vemos que tradicionalmente el espacio de la homosexualidad es el del ocultamiento, el lugar donde están ocultos los deseos y oculto también el anhelo de conservar un imaginario femenino tradicional; que funciona como proyección del deseo, como ocurre por ejemplo en el análisis del travestismo invertido en su crónica «Tarántulas en el pelo» (La Esquina 103). El travestismo invertido consiste en travestir al otro. En la fábula narrada en la crónica, son los peluqueros los que travisten de «barbie» a sus clientas, haciéndoles lo que ellos mismos quisieran hacerse.

Muchas veces el espacio ni siquiera necesita ser oculto ni privado. La segmentación geográfica da cuenta del apoderamiento del espacio público, el espacio apropiado del otro represor, que intenta ser reapropiado por el reprimido. Lugares dicotómicos que de noche develan al otro oculto durante el día. En «Anacondas en el parque» (La Esquina 21) la figura del pendex, un jovencito homosexual, se inmiscuye en las prácticas sexuales que además consideran positivamente el éxtasis de la persecución. De esta forma, hay una nueva perspectiva sobre el mismo hecho de la marginalidad, buscando en esto la eroticidad de lo prohibido. Es claramente una inversión de lo deseable, porque termina por desplazar lo permitido a la clasificación de cómodo, seguro, no erótico: lo aburrido. Claramente no se puede construir un erotismo desde el aburrimiento.

Ahora bien, esta literatura funciona como literatura otra, por lo que no puede entenderse de otra forma. Su discurso se compone de este anhelo por ser aceptada, pero dejaría de funcionar si lo fuera. Necesita por lo tanto seguir siendo literatura marginal. Esto lo podemos entender analógicamente a partir de la historia representada en la crónica que habla del circo Timoteo (La Esquina 131), en la que el público se burla de las actrices travestidas, haciendo parecer que no las respetan. Sin embargo, cuando el circo es llamado a presentarse en el Teatro Caupolicán va decayendo, porque esa aceptación bloquea el sentido mismo de este espectáculo otro, 
que necesita ser marginal, que necesita de la burla. La burla es para el circo Timoteo lo que el aplauso para el Caupolicán. Un problema de lenguaje; por eso la solución es volver a ese espacio desplazado que les permite seguir utilizando a su favor su forma travestida: "Así transforman la desventaja transexual en metales de aplausos» (La Esquina 137).

Tal como ocurrió con el circo Timoteo, la literatura marginal necesita ser marginal. La homosexualidad en las crónicas de Lemebel necesita ser esa homosexualidad para ser significativa. Por eso el proceso de inclusión de formas marginales desde el canon conlleva paralelamente el surgimiento de nuevas formas marginales. Siempre hay una parte de la literatura y de la sociedad que necesita pertenecer a la otredad para existir. Es en este lugar donde Lemebel sitúa estratégicamente su lugar de escritura, pero no meramente para representar lo marginal, sino para ir desestabilizando el orden de la ciudad y las identidades.

Recibido: el 20 de marzo de 2019; aceptado: el 24 de julio de 2019. 


\section{REFERENCIAS BIBLIOGRÁFICAS}

Bajtín, Mijail. «Introducción. Planteamiento del problema», en La cultura popular en la Edad Media $y$ en el Renacimiento. El contexto de Francois Rabelais. Trad. Julio Forcat y César Conroy, Madrid: Alianza, 1990, pp. 7-57.

Barthes, Roland. «¿Qué es la escritura?», en El Grado cero de la escritura. Trad. Nicolás Rosa, Buenos Aires: Siglo XXI, 2003, pp. 17-26.

Benjamin, Walter. «El Flâneur», en su Iluminaciones II. Trad. Jesús Aguirre, Madrid: Taurus, 1972, pp. 49-83. 7.

Blanco, Fernando. «Comunicación política y memoria en la escritura de Pedro Lemebel», en Blanco, Fernando (ed.), Reinas de Otro Cielo, Santiago: Lom, 2004, pp. 27-71.

Bourdieu, Pierre. ¿Qué significa hablar? Madrid: Akal, 1985.

CASTillo FAdic, M. Natalia. «El préstamo léxico y su adaptación: un problema lingüístico y cultural». Onomázein 7 (2002), pp. 469-496. <http://www.redalyc.org/pdf/1345/134518098024.pdf>.

De los Ríos, Valeria. «Crónica chilena contemporánea: Roberto Merino y Pedro Lemebel, de lo real y sus cicatrices». Persona y sociedad xx (2), (2006), pp. 127-141. <http://repositorio.uahurtado.cl/handle/11242/4023>.

Franco, Jean. «Apuntes sobre la crítica feminista y la literatura hispanoamericana». Hispanoamérica 45 (1986), pp. 31-43 <https://www.jstor.org/stable/20539210?seq=1\#page_scan_tab_contents>.

Franco, Jean. «Encajes de acero: la libertad bajo vigilancia», en Blanco, Fernando (ed.), Reinas de otro Cielo. Santiago: Lom, 2004, pp. 11-22.

Genette, Gérard. «Voz», en su Figuras III. Trad. Carlos Manzano, Barcelona: Lumen, 1989, pp. 270 321.

Halliday, M.A.K. El lenguaje como semiótica social. La interpretación social del lenguaje y del significado. Buenos Aires: Fondo de Cultura Económica, 2001.

Lakoff, George y Johnson, Mark. «Metáforas Ontológicas», en Metáforas de la vida cotidiana. Trad. Carmen González Marín, Madrid: Cátedra, 1995.

Lang, Mervyn F. Formación de palabras en español. Trad. Alberto Miranda Poza. Madrid: Cátedra, 1997.

Lemebel, Pedro. Loco afán. Crónicas de sidario. Santiago: Lom, 1997.

Lemebel, Pedro. La esquina es mi corazón. Santiago: Seix Barral, 2004.

Lemebel, Pedro. Adiós Mariquita Linda. Santiago: Sudamericana, 2005.

Mateo del Pino, Ángeles. «Chile, una loca geografía o las crónicas de Pedro Lemebel». Hispamérica 80-81 (1998), pp. 17-28.

Moareles Pettorino, Félix. Nuevo diccionario ejemplificado de chilenismos y de otros usos diferenciados del español de Chile. Santiago: Puntángeles, 2006.

Morales, Leonidas. "La mirada del testigo», en Novela chilena contemporánea. José Donoso y Diamela Eltit, Santiago: Cuarto Propio, 2004, pp. 55-81.

Olea, Raquel. «Tengo miedo torero. "Loca” de Transición». Manuscrito inédito. 2007.

Olea, Raquel. «Lengua mariflor y discurso homosexual. Políticas de oralidad y escritura en la obra de Pedro Lemebel». Conferencia inaugural del Magíster en Literatura Latinoamericana, 
Universidad Alberto Hurtado, 16 de abril de 2015. <https://soundcloud.com/filosofia-humanidades-uah/conferencia-lengua-mariflor-y-discurso-homosexual>.

Oroz, Rodolfo. «Sobre neologismos en la poesía de Gabriela Mistral», en sus Estudios mistralianos. Santiago: Universitaria, 2000.

Pastén B.J. Agustín. «Paseo crítico por una crónica testimonial: de La Esquina es mi corazón a Adiós mariquita linda de Pedro Lemebel». A Contra corriente 4:2 (2007), pp. 103-142. <https:// acontracorriente.chass.ncsu.edu/index.php/acontracorriente/article/view/275>.

Perlongher, Néstor (1997). «La barroquización (1988)», en Prosa plebeya, Buenos Aires: Colihue, 1997, pp. 113-117.

Rabanales, Ambrosio. «¿Qué es hablar correctamente?», en Castillo, Natalia y Pacheco, Pamela, Lengua Castellana y Comunicación, 1. ${ }^{\circ}$ medio, Santiago: Don Bosco, 2000, pp. 225-236.

Real Academia Española. Diccionario de la lengua española. Vigésima segunda edición (2001). <http://www.rae.es/>.

San Martín, Abelardo. «Procedimientos de creación léxica en el registro festivo del diario chileno La cuarta». Boletín de Filología de la Universidad de Chile xxxviI, 2:11 (2000), pp. 71-81.

Shкlovski, V. «El arte como artificio», en Todorov, Tzvetan (ed.), Teoría de la literatura de los formalistas rusos. Trad. Ana María Nethol, Buenos Aires: Siglo XXI, 2004, pp. 77-98.

Showalter, Elaine. «La crítica feminista en el desierto», en Fe, Marina (ed.), Otramente: lectura y escritura feministas, México: Fondo de Cultura Económica, 2001, pp. 75-111.

SpIvak, Gayatri Chakravorti. «¿Puede hablar el sujeto subalterno?». Trad. José Amícola. Orbis Tertius año III, 6 (1988), pp. 175-235.

Wigotski, Karina. «El discurso travesti o el travestismo discursivo en La esquina es mi corazón: Crónica urbana de Pedro Lemebel». Edición en línea <http://transexualia.org/wp-content/ uploads/2015/03/Apoyo_discursotravesti.pdf>. 